\title{
On the Value of Copying in the Teaching of Oil Painting Creation
}

\author{
Xia $\mathrm{Ma}^{1 *}$, Haikui $\mathrm{Ma}^{2}$ \\ ${ }^{1}$ Art Design and Jewelry Academy of Baoshan University, Baoshan City, Yunnan Province 678000, China \\ ${ }^{2}$ School of Government Baoshan University, Baoshan City, Yunnan Province 678000, China \\ *Corresponding author. Email:mhkmx@163.com
}

\begin{abstract}
At present, many oil painting teachers in colleges and universities do not attach importance to the copying, and the beginners do not understand the importance of the oil painting copying. However, copying is an important way to learn oil painting and can provide a lot of help to students in oil painting creation! Many famous oil painters enhance their learning of oil painting by copying; in the teaching of oil painting, copying the works of masters can effectively promote the students' learning and enable students to arouse the idea, language and emotion of creation by copying; and it is put forward that the teachers in colleges and universities shall pay attention to copying and take advantage of the value of copying during the teaching of oil painting creation, thus to promote the learning of students in oil painting creation and serve the teaching better.
\end{abstract}

Keywords: Copying, Oil Painting Creation, Teaching, Value.

\section{INTRODUCTION}

Copying is an important way to learn oil painting, many famous oil painters enhance their learning of oil painting by copying in the beginning of oil painting learning, thus to explore the language of oil painting creation. As copying can help learners to draw upon the strengths of others and learn the advantages of numerous masters, learners can learn the composition, skills, light sensation and color treatment, emotional expression of masters by copying. Both western and domestic painters gain the knowledge of masters by copying, and copying is also an important way for beginners to resolve the confusions in learning and gain knowledge [1-3]. In the manuscripts of Van Gogh compiled by the American H. Anna Suh, Van Gogh said in a private letter: "I really feel the necessity of learning from masters, such as Millet, Bretton, Brion and Boughton." In the private letters, he also mentioned that "At present, I think it is better to copy some good works than painting casually and groundlessly" [4-5]. By reading the notes and manuscripts of Van Gogh, we can see that Van Gogh copied the works of Millet and Bargue at the beginning, the copying of Millet's expression of themes and creation of characters as well as the copying of Bargue's strong lines have played a very important role in the creation of Van Gogh. The famous painters of $\mathrm{Xu}$ Beihong, Wu Zuoren and Zhou Bichu in China went to Europe to copy the classic original works in 1930s. Jin Shangyi, Quan Shanshi, Zhang Huaqing and other painters also went to Saint Petersburg to copy the classic originals when studying abroad in the Soviet Union. Yang Feiyun, the president of China Painting Academy, has twice organized the students of Chinese Academy of Oil Painting to the American Metropolitan Museum of Art and Russian Museum for field copying of classic original works, and he has also participated in copying. This shows that copying is a very effective way to learn oil painting creation. This is true for both masters and beginners!

\section{COPYING CAN AROUSE THE IDEA OF STUDENTS FOR CREATION.}

The idea of creation is the overall thinking of creation, such as: the creation theme, creation composition [6-7], creation language and treatment of color and light, but the direction of creation, selection of theme and the composition are particularly important, and many students stand still due to the failure in finding out the theme and direction of creation. 


\subsection{Explore the Direction of the Creation Materials by Copying}

Firstly, the creation themes are closely associated with the creation compositions, some materials are not suitable for the composition form of the traditional oil painting, but suitable for modern painting, and they are even a very good material, for example: In the painting works of Soutine, the composition of many works is not ideal from the perspective of traditional painting, but Soutine perfectly represents the materials so-called as composition "defects" by means of composition! However, the essence in the works can only be truly understood by copying, otherwise, the material and composition cannot be effectively combined, and the materials for creation will be limited. Therefore, the students are required to slowly understand the principle of composition and the selection of materials during the copying process [8]. Before copying, many students often lack the consciousness and materials of creation due to the lack of observation of the surrounding things, and by copying, they slowly find there are many materials for creation around, and start to think to combine some common things with the expressive techniques of modern oil painting for expression and master the feasibility of the selected materials by copying! The selection of materials is a big problem for students' creation, and most students always have no materials to choose just before creation, therefore, the teachers have to require the students to do a lot of copying and analyze the material selection of the masters' works, thus to facilitate the students to develop a habit of paying close attention to the surrounding things.

Secondly, by copying the character image and creating works of the same theme with the masters, Van Gogh was fascinated by Millet's character shaping with a rural theme, he copied Millet's character image for many times and created works in combination with the sketching. In the manuscripts of Van Gogh compiled by the American H. Anna Suh, he said: "I am looking forward to paint the character sketching of the male miners or female coal heavers after completing the copying of another two sets of works of Bargue, in this way, I can paint as long as I encounter characteristic models, which can be deemed as using use local materials", and he also said in a private letter: "I have drawn a farmer with a shovel, namely a digger, I have drawn five times at least, with various postures, besides, I have drawn two pictures of a sower and two pictures of a girl with broom, woman peeling potatoes with brimless felt hat, sheepherder leaning on crank rod...", from this, we can see that many of Van Gogh's works with a theme of farmer are mostly subject to Millet. His works with the same theme as Millet include: The First Step, The Sower, The Gleaners, Noon: Rest From Work and many other works with similar themes. Monet created the Lunch on the Grass in 1961, with the same name of a creation of Manet in 1863. Picasso created the Women of Algiers in their Apartment, with the same name of a creation of Delacroix. The works of these masters with the same name tell us that we can seek the theme and direction for creation by copying the works of masters with the same theme, innovate and inject new elements on the basis of copying to explore creation languages.

\subsection{Explore the Composition Form by Copying}

Many masters conduct copying at the beginning of learning, they learn the composition form of creation by copying and conduct creation of the same composition form in two ways, for example: The composition of the Garden In Flower At Sainte Adresse of Monet is almost the same as the composition of the Five-hundred Rakan Temple of Katsushika Hokusai [9], one of the three Japanese great masters of Ukiyoe, and the only difference lies in the technique of expression. The Lunch on the Grass of Monet and the Lunch on the Grass of Manet have the same composition. Thus, we can see that the learning of masters also starts from copying, and they learn the composition form by copying. The Five-hundred Rakan Temple is not an oil painting, but Monet appropriately combines the composition and language by learning different types of paintings. Therefore, the exploration of the composition form not only can be learned from the same type of paintings, but also can be learned from different types of paintings! Such a rule also exists in teaching, students always copying will have richer creation materials, more creation ideas and reasonable creation compositions, and can appropriately combine the creation composition and creation techniques. In the communication process with the students, the students always copying will often say: the scene of this painting is similar to somewhere else, or say: Such simple scene also can completely show the picture through composition! Van Gogh admires Millet most in the expression of rural theme and the depiction of farmers, and Van Gogh makes creation by constantly copying the creation of Millet and seeking the same sketching objects and themes. Many of his works express the rural themes, and most of them were inspired by the works of Millet with rural themes.

\section{COPYING IS BENEFICIAL TO THE LANGUAGE EXPLORATION IN THE OIL PAINTING CREATION}

Language exploration is the most difficult and important part in the creation! In most cases, many works fail in the creation due to the lack of their own language! However, the copying process of students is a process of technique and language analysis, and only by copying, can students seriously understand the 
techniques and language of the painters. Without practices, people often think they can do it in theory, but will find this is not the case in practices! During the copying process, students will have more profound thinking about the techniques and language, and will make a feasibility analysis of their own creation techniques or creation language. They will slowly have some profound understanding of the expression of language by constantly thinking of their own creation theme, practicing, combining the theory and practice and constantly experiencing the maters' creation language, and they will have some profound understanding and experience through some collisions during the process of copying works with different language. By constantly seeking their own creation language, their creation language will be more and more mature as time passes!

\subsection{Exploration of Technique Language}

Techniques for oil painting are like the legs for people, and every person learning the oil painting must master the basic language. For creation, the technique is required to have its own characteristics, so, the technique language of each painter are different, for example: the techniques of Van Gogh are loose, dynamic and alive, the technique language of Monet are overlaid and chromatographic contrast between light and shade and contrast between cold and warm, the color of Diebenkorn is interpenetrative, etc. Students have to constantly experience the language of these techniques during the copying process to comprehend how to make the color penetrate the color layer and how to use paint brushes to make the painting vivid and lively! All techniques have to be mastered by copying, and learning without copying will not master the techniques of the object and will be an armchair strategist! Copying is a major way to learn the technique language and is an important way. This is true for both masters and beginners! After oil painting is introduced to China, Chinese painters went abroad to copy the classic original works one after another, aiming to master the quintessence of masters in technique. The first, second and third generations of painters in China all have copying experience, such as Wu Zuoren, $\mathrm{Ai}$ Zhongxin, Jin Shangyi, Quan Shanshi, Zhang Huaqing, Luo Gongliu, Dong Xiwen, Zhan Jianjun, Zhu Naizheng, Yang Feiyun, Pang Maokun, Yu Xiaodong, Bai Yuping and Xie Dongming, and this shows that it is an effective measure to learn the techniques of oil painting by copying the works of masters and the excellent works of excellent painters.

\subsection{Exploration of Color Language}

Color is one of the most difficult languages to control in the creation, and students often raise many questions, for example, "Dear teacher, how do you express such sense of light? I think the color I adjusted when copying is very close to the original one, but why cannot I reach such effect? The sense of light is not reached and the color difference is also big!". In many cases, we can observe the warm and cold chromaticity as well as brightness of the color, but we will find by copying that there will be great differences in color between the copied painting and the original works. This is because the color is relative, and the chromaticity and brightness of the color will change with the ambient color. Therefore, it will be a thorny problem for creation if the chromaticity and brightness of color cannot be controlled, and the expected effect of the color will not be achieved! Copying is the only way to master the color language and color correlation of the masters, thus to explore the rules of color and master the color language skillfully. Only by constantly copying the works of the masters we like and studying the works of the masters to seek our own color, can we have our own independent color language in our creation.

The reason for Monet to become an impressionism master and change the history of oil painting and his own destiny is his inspiration obtained after contacting and copying Japanese Ukiyoe illustrations! He was fascinated in the color of Japanese Ukiyoe after contacting illustrations of Ukiyoe, he often copied the works of Ukiyoe, studied the color of Ukiyoe in combination with his creation, and formed his own impressionistic style.

\section{COPYING IS BENEFICIAL TO THE EXPLORATION OF EMOTIONAL EXPRESSIONS IN CREATION}

A creation without emotion is like a person without vital signs! However, the emotion may not be expressed or expressed properly by every beginner during creation, and the expression of emotion is closely related to the living background and living environment of the painter, and related to the expression skills and techniques of the painter. The living background and living environment are brought up by the painter himself, while the emotion in the works can only be expressed by the painter with certain skills and techniques. Such skills and techniques have to be constantly felt and experienced by copying and practicing before being applied to the creation.

The emotion of the picture can be expressed in many ways: the way to express emotion by composition, the way to express emotion by painting brushes, the way to express emotion by painting style, the way to express emotion by character image, the way to express emotion by color and the way to express emotion by light. Each kind of different expression way is directly related to the emotion to be transmitted by the painter, and in a word, each way aims to express the theme of the picture and the mood of the painter! No matter the emotional thoughts and feelings are expressed by composition, 
brush, color, light or the shaping of character image, all have to be constantly experienced by copying. For example: The level of the horizon line and viewpoint in the composition will make the viewer produce different feelings, therefore, the painters will use extremely unstable composition to express the emotional feeling when there is any need to express the anxious emotion. For example: In the Chirstina's World, a work of Wyeth, the horizon line is very high, which slightly expresses the mentalities of the leading character, such as anxiety, loneliness, confusion, recreance, melancholy and helplessness, and the author painted houses on the top of the mountain, providing a metaphor of family and the mentalities of confidence, hope and warmth; Van Gogh is the most representative painter to express emotions by brush strokes, he always copies the works of Bargue before starting a figure drawing every time and wishes to learn Bargue's strong lines by copying his works! Secondly, to learn Millet's expression of themes and shaping of characters, Van Gogh copies the character shape of the works of Millet with a rural theme and learns the emotional expression of farmer images.

\section{CONCLUSIONS}

Teachers shall pay attentions to the values of copying in the teaching process of oil painting, copying can enhance the basic skills of the students, facilitating them to skillfully master the techniques of oil painting and explore their own technique language, color language and emotion for creation in combination of the oil painting copying and the practice as well as the personal creation. The combination of copying and teaching practice during teaching can promote the teaching effect, facilitating students to develop more steadily during the creation process and improve the creation effect to a higher level.

\section{REFERENCES}

[1] H. Anna Suh, Manuscripts of Van Gogh, [M]. Beijing United Publishing Co., Ltd. 2018.4

[2] Yao Dongyu, Simple Analysis of the Importance of Copying on Creation, [J]. Shenhua (Shang), 2021.09

[3] Li Yanqing, Significance and Methods of Modern Oil Painting Copying, [J], Art Observation. 2019.08

[4] Cheng Yongjun, Emotional Teaching of Copying Courses of Classic Oil Painting, [J]. Northwest Fine Arts. 2020.03

[5] Cui Zhiqiang, Values and Teaching Reform of Oil Painting Copying, [J]. Art Education Research. 2021.10

[6] Zhang Yuming, Discussion on How to Train Students' Integral Consciousness during the Teaching of Oil Painting Creation in Colleges and Universities, [J]. Art Evaluation, 2020.10
[7] Kang Jingdan, On the Importance of Copying Courses in the Teaching Process of Oil Painting, [J]. Fine Arts Literature, 2020.03

[8] Dong Tao, Analysis of the Importance of Copying Courses in the Teaching Process of Oil Painting, [J]. Daguan (Forum), 2019.04

[9] Li Panpan, Research of Copying Courses of Classic Oil Paintings in the Teaching Reform of Art Institutions, [J]. Ability and Wisdom. 2020.18 